\title{
Simultaneous Follicular Lymphoma and Myelofibrosis: Report of a Case with Review of the Literature
}

\author{
Ling-zhijie Kong $\mathbb{D}^{1,2}$ \\ Jing $\mathrm{Li}^{3}$ \\ Rui-Cang Wang ${ }^{\prime}$ \\ Lin Kang ${ }^{4}$ \\ Qiang Wei ${ }^{5}$ \\ Yan $\mathrm{Li}^{1}$
}

'Department of Haematology, Hebei General Hospital, Shijiazhuang, Hebei, People's Republic of China; ${ }^{2}$ Hebei North University, Zhangjiakou, Hebei, People's Republic of China; ${ }^{3}$ Department of Hematology, Hebei Province Hospital of Chinese Medicine, Shijiazhuang, Hebei, People's Republic of China; ${ }^{4}$ Department of Pathology, Hebei General Hospital, Shijiazhuang, Hebei, People's Republic of China; ${ }^{5}$ Department of Nuclear Medicine, Hebei General Hospital, Shijiazhuang, Hebei, People's Republic of China
Correspondence: Yan Li

Department of Haematology, Hebei

General Hospital, No. 348, Heping West

Road, Shijiazhuang, Hebei, 05005I,

People's Republic of China

Tel +8618931866300

Email liyan98_win@163.com
Background: Myelofibrosis (MF) is often associated with chronic myeloid leukemia, myelodysplastic syndrome and primary myeloproliferative neoplasms (MPN), but few number cases of malignant lymphoma with myelofibrosis was reported, and a few cases about follicular lymphoma with MF were found. Here we described a case of follicular lymphoma (FL) complicated by myelofibrosis.

Case Presentation: A 43-year-old man was diagnosed with follicular lymphoma (FL) complicated by MF, besides, the lymphoma staging of this patient was AnnArbor IV B. The cytokines of plated-derived growth factor (PDGF), basic fibroblast growth factor (b-FGF), vascular endothelial growth factor (VEGF), tumor necrosis factor $\alpha$ (TNF- $\alpha$ ), interleukin-1 $\beta$ (IL-1 $\beta$ ), interleukin-2 (IL-2), and transforming growth factor- $\beta$ (TGF- $\beta$ ) were positive, while JAK2V617F, MPL, and CALR mutations were negative. After first course of chemotherapy, the peripheral blood and MF improved. The systemic superficial lymph nodes and spleen were significantly narrowed after the third cycle of chemotherapy.

Conclusion: The production of various cytokines, such as b-FGF, TNF- $\alpha$, TGF- $\beta$, PDGF, IL-1 $\beta$, IL-2, IL-6, IL-10, may contribute to the development of MF.

Keywords: follicular lymphoma, myelofibrosis, immunohistochemistry, cytokines

\section{Introduction}

We described a case report of simultaneous follicular lymphoma with myelofibrosis, which leads to a serious of problem in diagnosis, etiology and treatment, and promotes us to critically review the literature. Follicular lymphoma (FL) is the second most common lymphoma in western countries, accounting for about $35 \%$ of all of non-Hodgkin's lymphoma (NHL). ${ }^{1,2}$ In China, follicular lymphoma accounts for a slightly lower proportion of non-Hodgkin's lymphoma, but it is still a common type. ${ }^{3}$ Follicular lymphoma is an indolent B-cell lymphoma typically presenting with diffuse lymphadenopathy, bone marrow involvement, and splenomegaly. Extranodal involvement is less common. $^{2}$ The majority of FL patients have the characteristic of $t(14 ; 18)$ $(\mathrm{q} 32 ; \mathrm{q} 21)$ translocation, which results in the overexpression of the BCL-2 protein. ${ }^{4}$ In most cases, immunohistochemical staining is positive for CD19, CD20, CD10, monoclonal immunoglobulin and bcl-2 protein. ${ }^{2}$ Myelofibrosis $(\mathrm{MF})$ is characterized by the increase in BM stromal fibers composed of 
reticulin and collagen. ${ }^{5} \mathrm{~A}$ wide variety of hematological malignancies result in myelofibrosis, including chronic myeloid leukemia, acute megaloblastic leukemia, hairy cell leukemia and myelodysplastic syndrome. But MF complicated with malignant lymphoma is rare, ${ }^{6}$ and we found a few case reports of FL with myelofibrosis. ${ }^{7,8}$

\section{Case Presentation}

A 43-year-old-man presented us with enlarged lymph nodes from May 2020, and he was treated at the local hospital. Then he developed sore limbs and pancytopenia, therefore, he was referred to our department in late August. A detailed medical history was collected: body temperature $36.6^{\circ} \mathrm{C}$, pulse $88 /$ minute, respiration $22 /$ minute, blood pressure 128/69 mmHg, clear consciousness, pallor of the complexion and palpebral conjunctiva, and splenomegaly. A few enlarged lymph nodes were palpable in bilateral cervical, axillary and inguinal regions, the largest of which measuring about $4 \mathrm{~cm}$ in size is located in the right inguinal region. The main symptom of this patient is significant splenomegaly and pancytopenia.

The laboratory findings at the time of admission are shown in Table 1 . His serum levels of LDH, $\beta 2$ microglobulin and IL-6 were elevated. In addition, his serum level of vascular endothelial growth factor (VEGF) was normal (Figure 1). The detection of EB virus was negative. Flow cytometry (FC) was performed on the peripheral blood specimen because of dry tap aspiration. Monoclonal B lymphocytes accounted for $1.47 \%$ of karyocyte in peripheral blood samples. The aberrant lymphocytes population expressed CD19, CD20, CD10, FMC7, CD81, cKappa, and partially expressed CD79b, CD200, CD22, CD1d, sIgM but did not express CD11c, CD103, CD5, CD23, CD43, CD38, CD25, sIgD, cLambda, and CD138. The immunophenotyping by FC was consistent with the phenotype of CD5-, CD10+ monoclonal B lymphocytes (Figure 2). The biopsy of right cervical lymph node combining with the immunohistochemistry supported the diagnosis of follicular lymphoma (3A). Immunostaining revealed that the tumor cells were positive for CD20, CD79 $\alpha$, Bcl-2, Bcl-6, CD10, PAX5, CD5 (Interfollicular region), CD3 (Interfollicular region), CD43 (Interfollicular region), CD21 (FDC net), CD23 (FDC net), MUM-1, VEGF, b-FGF, TNF$\alpha$, TGF- $\beta$, PDGF, IL-1 $\beta$, IL-2, IL-6, IL-10 and negative
Table I The Laboratory Findings

\begin{tabular}{|c|c|c|}
\hline CRP & CRP & $35.19 \mathrm{mg} / \mathrm{L} \uparrow$ \\
\hline CBC & $\begin{array}{l}\text { WBC } \\
\text { NE } \\
\text { LY } \\
\text { EO } \\
\text { RBC } \\
\text { Hb } \\
\text { PLT }\end{array}$ & $\begin{array}{l}1.36 \times 10^{9} / \mathrm{L} \downarrow \\
0.88 \times 10^{9} / \mathrm{L} \downarrow \\
0.32 \times 10^{9} / \mathrm{L} \downarrow \\
0.01 \times 10^{9} / \mathrm{L} \downarrow \\
1.93 \times 10^{12} / \mathrm{L} \downarrow \\
57.00 \mathrm{~g} / \mathrm{L} \downarrow \\
59.00 \times 10^{9} / \mathrm{L} \downarrow\end{array}$ \\
\hline ESR & ESR & $97 \mathrm{~mm} / \mathrm{h} \uparrow$ \\
\hline Coagulation & $\begin{array}{l}\text { Fbg } \\
\text { DD }\end{array}$ & $\begin{array}{l}4.35 \mathrm{~g} / \mathrm{L} \uparrow \\
1.93 \mathrm{mg} / \mathrm{L} \mathrm{FEU} \uparrow\end{array}$ \\
\hline Coombs test & $\begin{array}{l}\text { Direct Coombs test } \\
\text { Indirect Coombs } \\
\text { test }\end{array}$ & $\begin{array}{l}\text { Negative } \\
\text { Negative }\end{array}$ \\
\hline$\beta 2$ microglobulin & $\beta 2-M G$ & $4.58 \mathrm{ug} / \mathrm{mL} \uparrow$ \\
\hline ANA & ANA & $\begin{array}{l}\text { Weak positive } \\
\mathrm{I}: 100\end{array}$ \\
\hline $\mathrm{RCT}$ & RCT\% & $3.16 \% \uparrow$ \\
\hline Biochemistry & $\begin{array}{l}\text { T.P } \\
\text { GLOP } \\
\text { ALP } \\
\text { LDH } \\
\text { HBD } \\
\text { Mb } \\
\text { FBG } \\
\text { P } \\
\text { Mg } \\
\text { Uric acid } \\
\text { TG } \\
\text { HDL } \\
\text { Apo Al }\end{array}$ & $\begin{array}{l}63.4 \mathrm{~g} / \mathrm{L} \downarrow \\
19.8 \mathrm{~g} / \mathrm{L} \downarrow \\
125.8 \mathrm{U} / \mathrm{L} \uparrow \\
488.1 \mathrm{U} / \mathrm{L} \uparrow \\
360.4 \mathrm{U} / \mathrm{L} \uparrow \\
77 \mathrm{ng} / \mathrm{mL} \uparrow \\
7.16 \mathrm{mmol} / \mathrm{L} \uparrow \\
1.74 \mathrm{mmol} / \mathrm{L} \uparrow \\
0.73 \mathrm{mmol} / \mathrm{L} \downarrow \\
506.5 \mathrm{umol} / \mathrm{L} \uparrow \\
1.85 \mathrm{mmol} / \mathrm{L} \uparrow \\
0.70 \mathrm{mmol} / \mathrm{L} \downarrow \\
0.93 \mathrm{~g} / \mathrm{L} \downarrow\end{array}$ \\
\hline $\begin{array}{l}\text { Serum iron } \\
\text { metabolism }\end{array}$ & $\begin{array}{l}\text { Fer } \\
\text { UIBC }\end{array}$ & $\begin{array}{l}581.4 \mathrm{ng} / \mathrm{mL} \uparrow \\
55.00 \mathrm{umol} / \mathrm{L} \uparrow\end{array}$ \\
\hline Interleukin-6 & IL-6 & $17.10 \mathrm{pg} / \mathrm{mL} \uparrow$ \\
\hline
\end{tabular}

Notes: $\uparrow$ Denotes above the upper limit of the reference range, $\downarrow$ denotes below the lower limit of the reference range.

Abbreviations: $C B C$, complete blood count; CRP, C-reactive protein; WBC, white blood cell; NE, neutrophil; LY, lymphocyte; Eo, eosinocyte; RBC, red blood cell; Hb, hemoglobin; PLT, plate; ESR, erythrocyte sedimentation rate; Fbg, fibrinogen; DD, Ddimer; RCT, reticulocyte; T.P, total protein; GLOB, globulin; ALP, alkaline phosphatase; $\mathrm{LDH}$, lactate dehydrogenase; HBD, hydroxybutyrate dehydrogenase; Mb, myoglobin; GLU, FBG, fasting blood glucose; TG, triglyceride; HDL, high density lipoprotein; Apo AI, Apolipoprotein AI; Fer, ferritin; UIBC, unsaturated iron binding capacity; IL-6, interleukin-6.

for SOX-11, CD38, CD138, Kappa, Lambda, CyclinD1. Ki-67 stain showed nuclear positivity in $60 \%$ nodal tumour cells and 30\% extranodal tumour cells (Figure 3) 


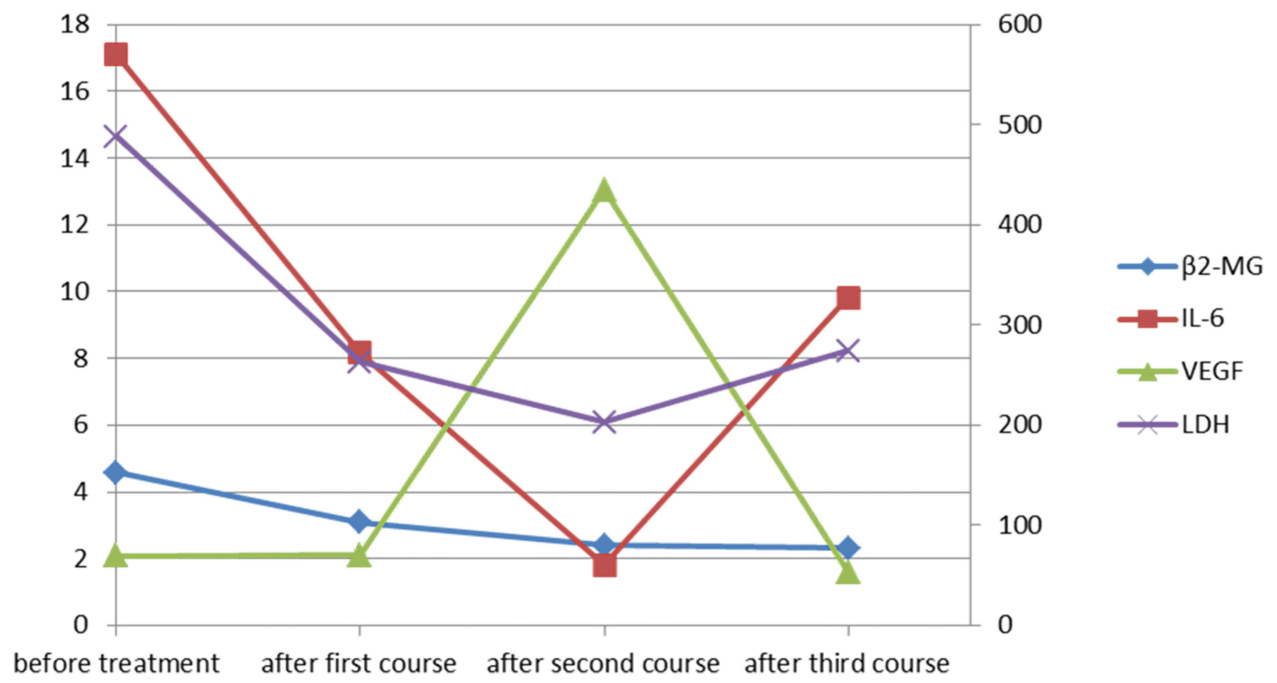

Figure I The changes of $\beta 2-M G$, IL-6, VEGF, LDH. The series of $\beta 2-M G$, IL-6 are drawn on the primary axis, and the series of VEGF, LDH are drawn on the secondary axis.

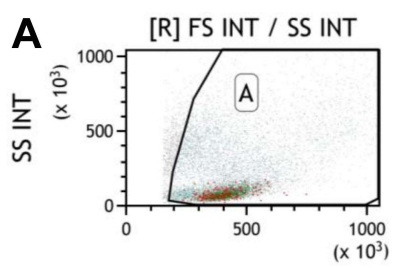

FS INT

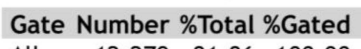

$\begin{array}{llll}\text { All } & 12,279 & 81.86 & 100.00\end{array}$

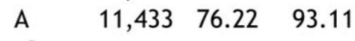

C.

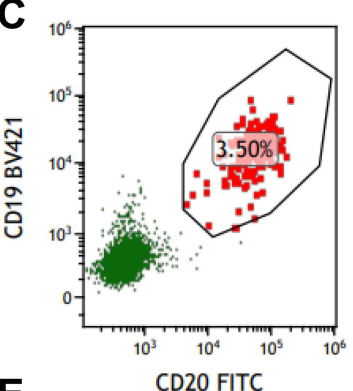

E

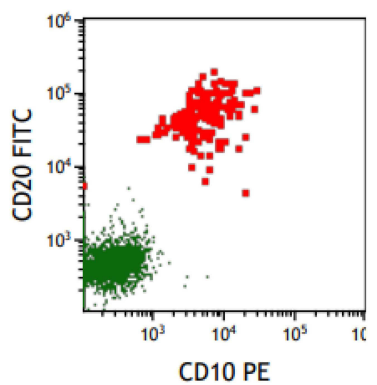

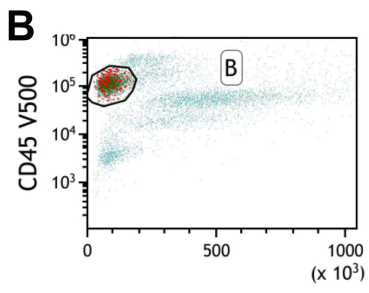

SS INT

Gate Number \%Total \%Gated

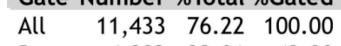

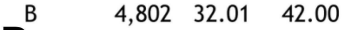

D $10^{6} \mathrm{C}-+: 94.63 \%$

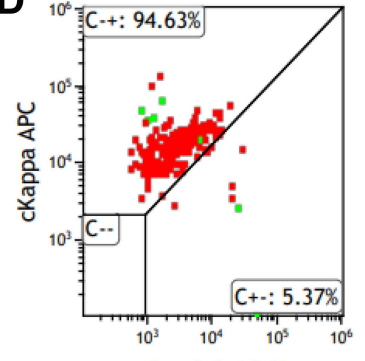

$\mathbf{F}$

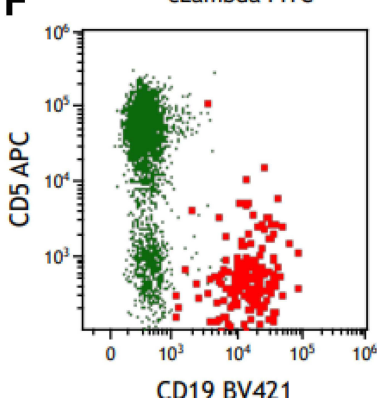

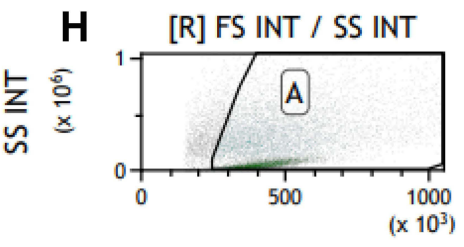

FS INT

Gate Number \%Total \%Gated

$\begin{array}{llll}\text { All } & 13,836 & 92.24 & 100.00\end{array}$

A $\quad 11,726 \quad 78.17 \quad 84.75$

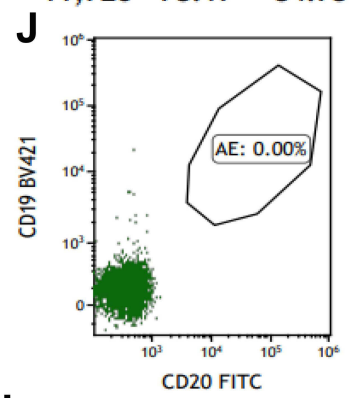

$\mathbf{L}$

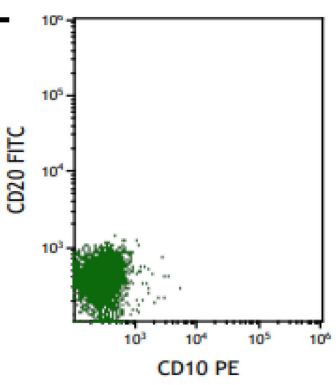

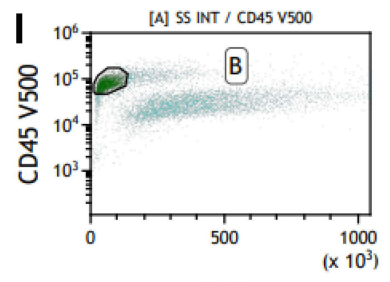

SS INT

Gate Number \%Total \%Gated

$\begin{array}{llll}\text { All } & 11,726 & 78.17 & 100.00\end{array}$

$\begin{array}{llll}\text { B } & 3,929 & 26.19 & 33.51\end{array}$

$\mathbf{K}_{10}$

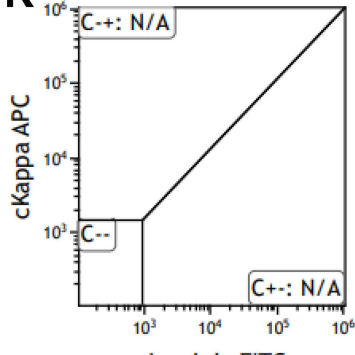

M

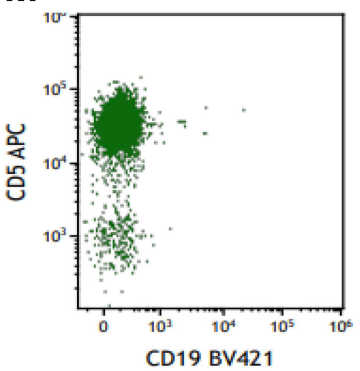

Figure 2 Flow cytometry of peripheral blood. (A-F) Before chemotherapy, the aberrant lymphocytes population expressed CDI9, CD20, CDI0, cKappa; (H-M) after three courses of chemotherapy, these became negative. 


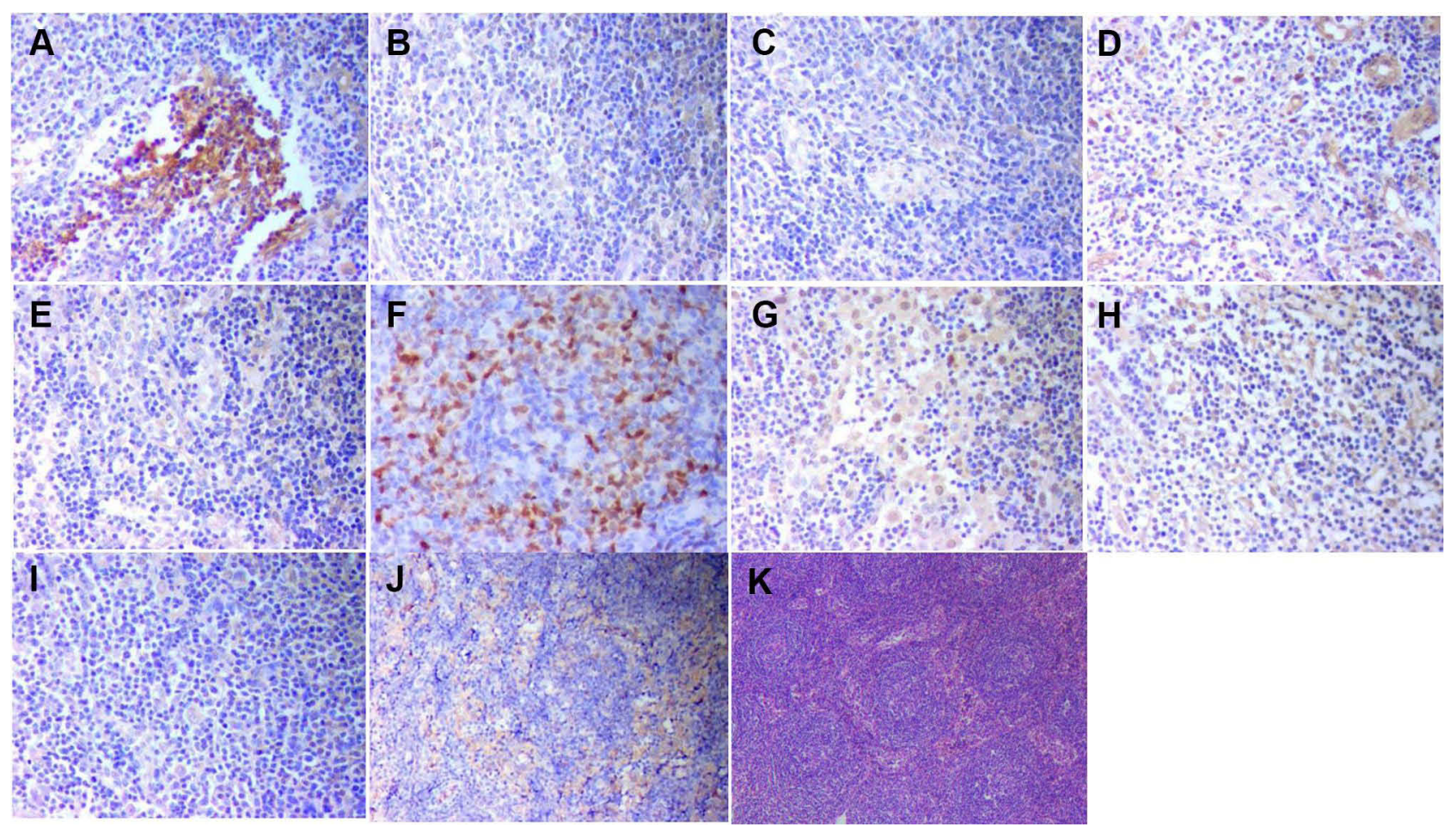

Figure 3 The immunostaining of right cervical lymph node for cytokines. (A) (b-FGF; $\times 200)$, positive; (B) (IL- I $\beta ; \times 200)$, positive; (C) (IL-2; $\times 200)$, positive; (D) (IL-6; $\times 200)$, positive; (E) (IL-10, $\times 200)$, positive; (F) (MUM-I $\times 200)$, positive; (G) (PDGF $\times 200)$, positive; (H) $($ TGF- $\beta \times 200)$, positive; (I) (TNF- $\alpha \times 200)$, positive; (J) $($ VEGF $\times 200)$, positive; (K) $\mathrm{HE}, \times 40$.

Bone marrow aspiration yielded a dry tap, and the bone marrow biopsy showed active myeloproliferative activity. Granulocytes were rare, mainly in the mature stage; erythroid cells were rare, mainly middle and late erythrocytes; the number of megakaryocytes was normal, mainly polymorphonuclear cell; the proliferation of lymphocytes was active, and the proliferation of collagen fibers can be seen in mesenchymal tissue of bone marrow. The immunostaining showed that the aberrant lymphocytes population was positive for CD34, CD117, CD61, CD3, CD20, CD138, E-CAD, MPO, CD45RA, VEGF, b-FGF, TNF- $\alpha$, TGF- $\beta$, PDGF, IL-1 $\beta$, IL-2, IL-6, IL-10. The reticular fiber staining was grade 3 (Figure 4). Bone marrow examination of our hospital showed atypical lymphocytes, accounting for about $80 \%$ of lymphocytes. And the peripheral blood smear showed tear-drop cells. The PET images were consistent with the performances of AnnArbor IV: General hypermetabolic enlarged lymph nodes were be seen in both sides of diaphragm, especially in the abdomen; the metabolism of bone marrow and left kidney was elevated. In addition, the
PET scan showed splenomegaly obviously without hypermetabolism, which were induced by MF probably (Figure 5). The patient underwent peripheral blood examinations for JAK2, MPL, and CALR mutations, and all of these are negative. Fluorescence in situ hybridization (FISH) analysis performed on paraffin embedded tissue sections from the right cervical lymph node were positive for the BCL2 (18q21) split signal and IGH/BCL2 fusion signal, and negative for MYC rearrangement and BCL6 (3q27) split signals (Figure 6).

Based on those, the patient was diagnosed with FL (3A, AnnArbor IVB) complicated by MF. In the first course of chemotherapy, the patient received the R-COP therapy (rituximab 700mg, ivgtt: day 0; cyclophosphamide $600 \mathrm{mg}$, ivgtt: day 1 ; vindesine $3 \mathrm{mg}$, ivgtt: day 1 ; prednisone $100 \mathrm{mg}$, p.o: day 1-5). After the improvement of hemogram, he was given the R-CHOP therapy (rituximab 700mg, ivgtt: day 0; cyclophosphamide $800 \mathrm{mg}$, ivgtt: day 1; doxorubicin $60 \mathrm{mg}$, ivgtt: day 1 ; vindesine 4mg, ivgtt: day 1; prednisone $100 \mathrm{mg}$, p.o: day $1-5)$. During the second course, the patient developed 


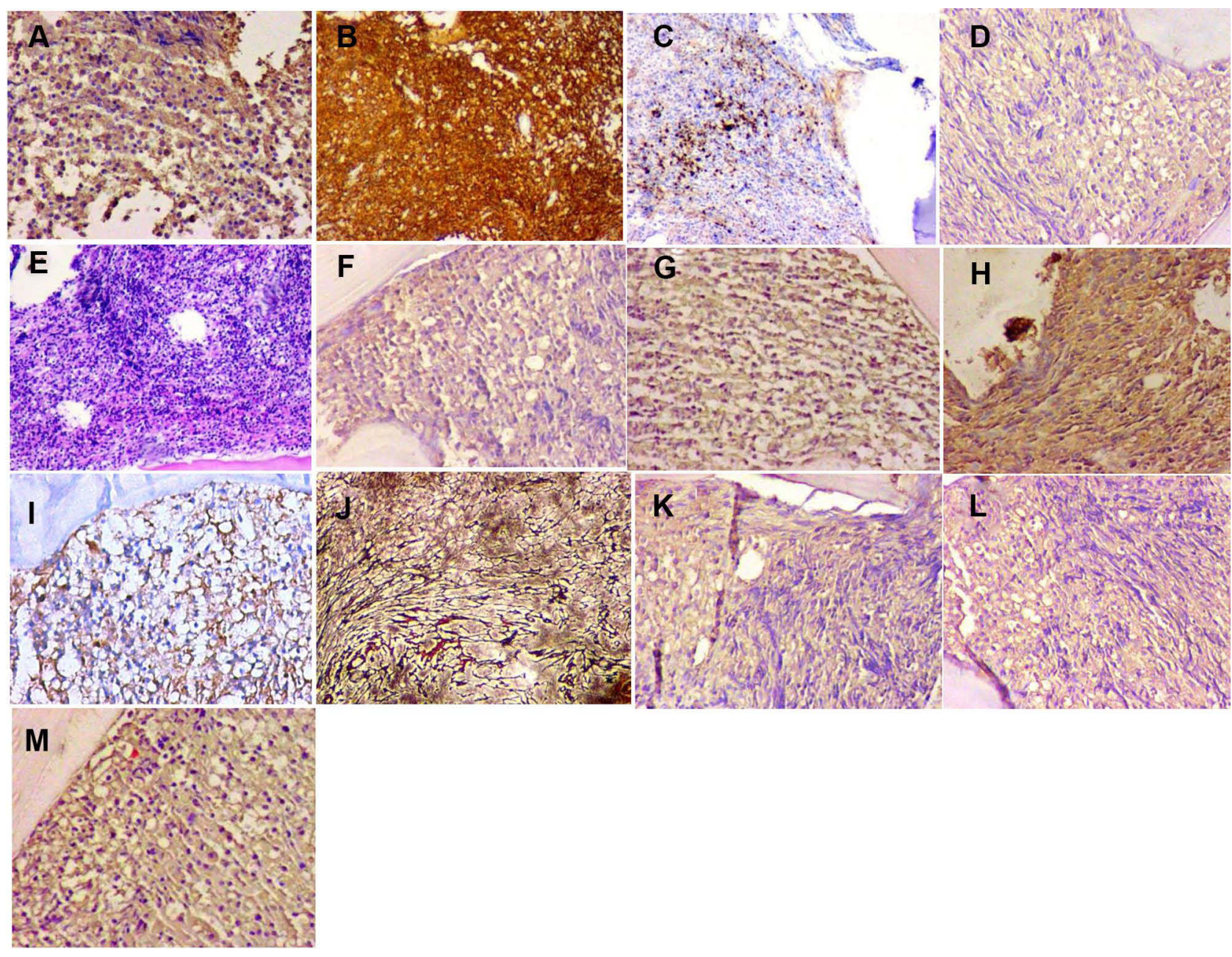

Figure 4 The immunostaining of bone marrow before treatment. (A) (b-FGF; $\times 200)$, positive; (B) (CD20; $\times 100)$, positive; (C) (CD6I×I00), positive; (D) (IL-I0; $\times 200)$, positive; (E) HE I00×; (F) (IL-I $\beta ; \times 200)$, positive; (G) (PDGF $\times 200)$, positive; (H) (TGF- $\beta \times 200)$, positive; (I) (VEGF $\times 200)$, positive; (J) reticular fiber staining revealed diffuse fibrosis (MF-3) 100×; (K) (IL-2;×200), positive; (L) (IL-6;×200), positive; (M) (TNF- $\alpha \times 200)$, positive.

serious adverse gastrointestinal reactions, so prednisone was replaced by methylprednisolone. The pancytopenia was responding well to treatment (Table 2). The immunostaining of bone marrow showed the tumor cells were negative for CD19, CD117, b-FGF, TNF- $\alpha$, TGF- $\beta$, PDGF, IL-1 $\beta$, IL-2, IL-6, IL-10, except for VEGF after two courses (Figures 7 and 8). After the first course, the MF in the bone marrow improved. The reticular fiber staining was grade 1 (Figure 7). And the serum LDH, $\beta 2-\mathrm{MG}$ and IL-6 levels were declined, but these parameters were still higher than that in normal cases. After two courses of chemotherapy, the serum levels of LDH, $\beta 2-\mathrm{MG}$ and IL-6 continued to fall to normal levels. However, the serum VEGF level elevated a lot. After the third course, VEGF level was declined, but IL-6 and
LDH elevated again (Figure 1). Meanwhile, the serum levels of IL-1 $\beta$, IL- 8 , IL-10, TNF- $\alpha$ were normal. The PET images showed improvement of the lymphadenopathy (Figure 5).

\section{Discussion}

MF can occur not only after lymphoma, but also at the same time or earlier than lymphoma. ${ }^{9}$ However, when MF occurs at the same time with lymphoma, we cannot make a final diagnosis of primary myelofibrosis (PMF) or secondary myelofibrosis (SMF) easily. Analyses of JAK2, MPL, and CAL mutations are highly specific for the diagnosis of PMF. Ninety percent of PMF patients can be detected a mutation among three genes. However, the triple-negative result of gene mutations in 

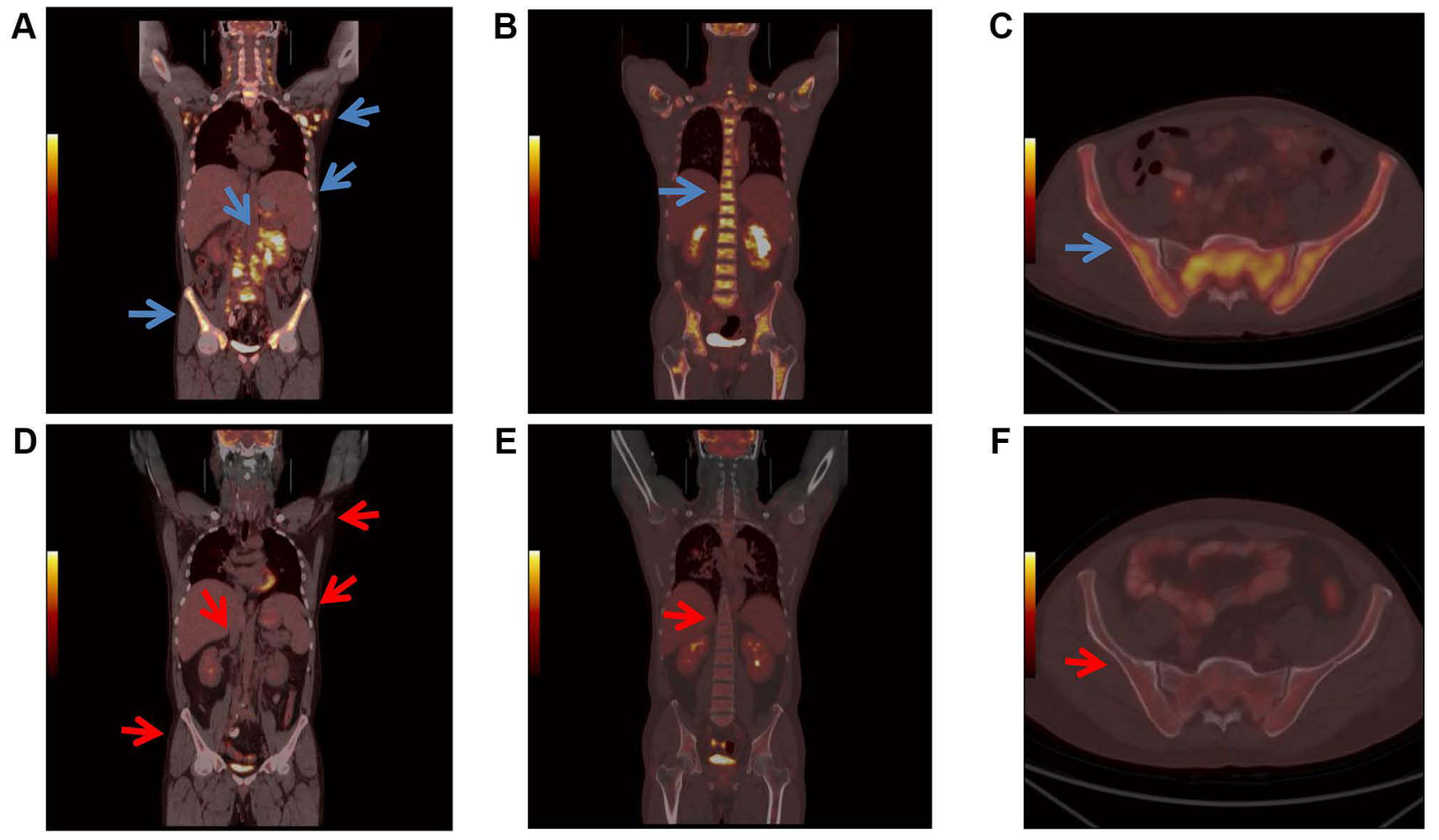

Figure 5 PET/CT finding. (A-C) Before chemotherapy. (The largest lymph nodes was in the lower abdominal mesenteric region 68mm $x$ 42mm, SUVmax =8.2). (D-F) After three courses of chemotherapy (The spleen reduced obviously, whose metabolism was normal (SUVmax=2.6)). (A) Widespread lymph node enlargement and hypermetabolism, splenomegaly, kidney hypermetabolism (blue arrows) and diffuse bone marrow hypermetabolism. Its inferior border approached the upper margin of pelvis (SUVmax= 2.9); (B) spinal hypermetabolism (blue arrow); (SUVmax =9.0); (C) iliac hypermetabolism (blue arrows); (D) no abnormal lymph nodes were found. The volume of spleen was smaller than before, and the metabolism of bone marrow, kidney metabolism were normal (red arrows); (E) normal spine metabolism, (SUVmax =3.3) (red arrow); (F) normal ilium metabolism (red arrows).

our case cannot make us reach a final definite decision since $10 \%$ patients with PMF have none of mutation in these three genes. Thus, we could not distinguish triplenegative PMF from SMF. ${ }^{10,11}$ However, in this case, the diagnosis of primary myelofibrosis lacks necessary criteria: presence of megakaryocytic proliferation and atypia; presence of another clonal marker in the absence of JAK2, CALR, or MPL mutation. ${ }^{12}$ Meanwhile, the MF improved after the chemotherapy for FL. Therefore, the patient was diagnosed with SMF. The pathological mechanisms of MF in patients with malignant lymphoma remains unclear, intensive studies are required in this condition. The main causes of MF are cytokines and growth factors, especially those related to fibrogenic properties, such as TGF- $\beta$, IL-1, PDGF and so on. ${ }^{13}$ And some studies have revealed that cytokines including TGF- $\beta$, b-FGF and PDGF may play an important role for the $\mathrm{MF}$ associated with malignant lymphoma. $^{14}$
As we know, a total of 49 cases of lymphoma with myelofibrosis have been reported except the present case, including 5 cases of Hodgkin lymphoma, 25 cases of Non Hodgkin's T-cell lymphoma and 19 cases of Non Hodgkin's B-cell lymphoma. There have been a few cases of FL complicated with MF among these cases. $^{7,8}$ The development of the MF are associated with the production of various cytokines, such as TGF- $\beta$, IL1, PDGF, b-FGF, VEGF. ${ }^{13,15}$ However, the accurate cause of MF with concurrent lymphoma is not clear yet. It was reported that MF may be attributable to the lymphoma cells producing PDGF in a case of angioimmunoblastic T-cell lymphoma (AITL) with complicating MF. Meanwhile, the b-FGF produced by the bone marrow megakaryocytes was considered as an irrelevant factor of the development of concurrent MF. ${ }^{15}$ On the contrary, another report showed that b-FGF played an important role in the case of MF complicated with peripheral $\mathrm{T}$ cell lymphoma (PTCL). ${ }^{16}$ In addition, 

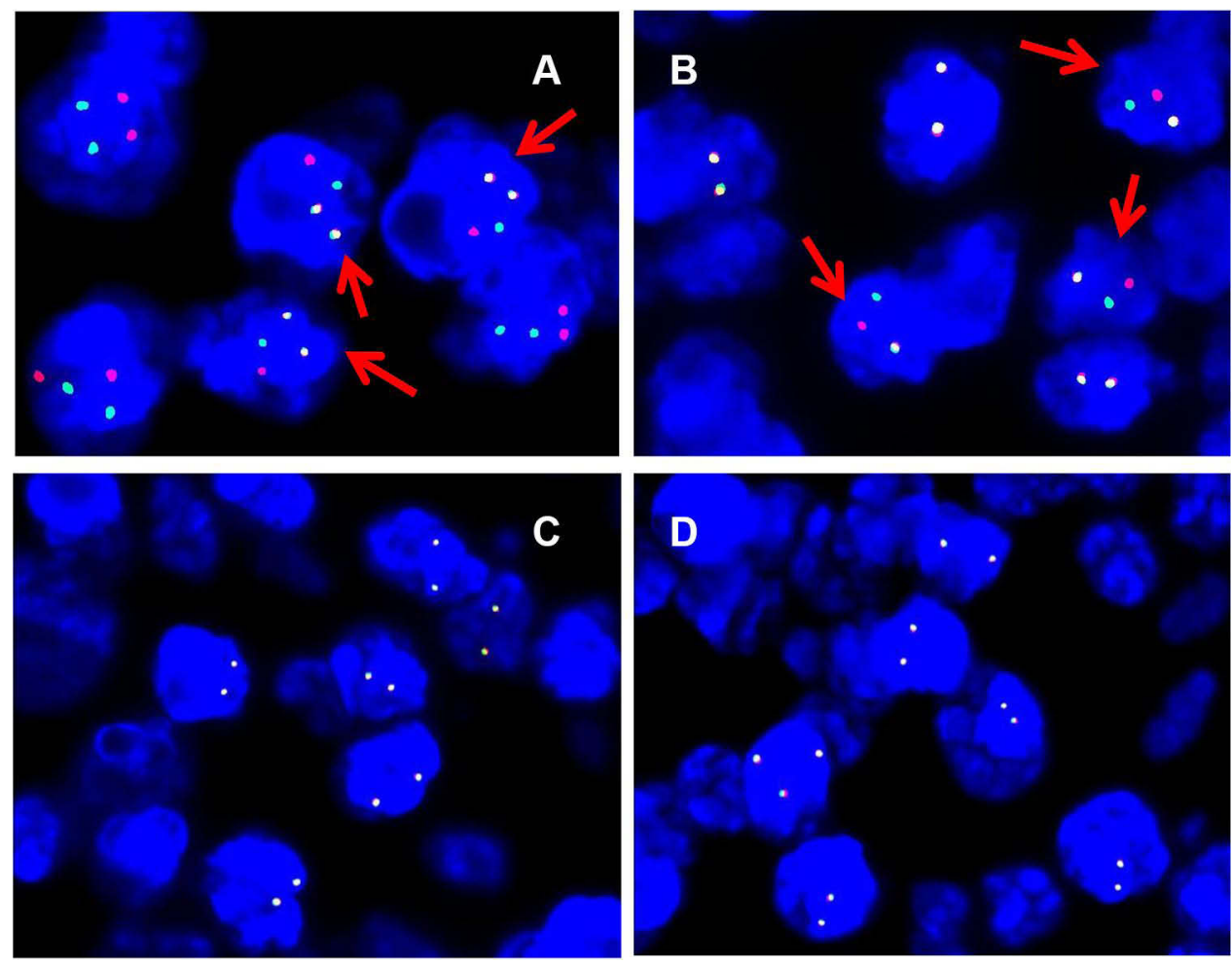

Figure 6 Fluorescence interphase in situ hybridization on lymph node biopsy. (A) IGH-BCL2 dual-colour dual-fusion probe displays two fused green and red signals, one isolated green and one isolated red signal in most of tumour nuclei with $t(\mid 4 ; 18)(q 21 ; q 32) / I G H-B C L 2$. Arrow indicates positive nuclei. (B) BCL2 dual-colour break-apart (BAP) probe shows one co-localised green and red signal, one isolated green and one isolated red signal in most of tumour nuclei; (C) BCL6 dual-colour break-apart (BAP) probe shows two co-localised green and red signal; (D) MYC dual-colour break-apart (BAP) probe shows one co-localised green and red signal.

there were a few other case reports consenting to the contribution of cytokines. In a report of peripheral $\mathrm{T}$ cell lymphoma-not otherwise specified (PTCL-NOS) with myelofibrosis, the cytokines of PDGF, TNF- $\alpha$, and TGF- $\beta$ made a contribution to simultaneous MF, but VEGF was not associated with the presence of the MF. ${ }^{14}$ Besides that, several cases implicated that TGF$\beta$ were associated with simultaneous MF. ${ }^{17-20}$

As previously described, the expression of these cytokines was immunohistochemically performed to explore the mechanism of simultaneous MF with malignant

Table 2 The Analysis of Peripheral Blood

\begin{tabular}{|l|c|c|c|c|}
\hline & $\begin{array}{c}\text { Before } \\
\text { Treatment }\end{array}$ & $\begin{array}{c}\text { After } \\
\text { First } \\
\text { Course }\end{array}$ & $\begin{array}{c}\text { After } \\
\text { Second } \\
\text { Course }\end{array}$ & $\begin{array}{c}\text { After } \\
\text { Third } \\
\text { Course }\end{array}$ \\
\hline $\mathrm{RBC}$ & $1.93 \times 10^{12} / \mathrm{L}$ & $3.29 \times 10^{12} / \mathrm{L}$ & $4.01 \times 10^{12} / \mathrm{L}$ & $4.04 \times 10^{12} / \mathrm{L}$ \\
$\mathrm{Hb}$ & $57.00 \mathrm{~g} / \mathrm{L}$ & $97.00 \mathrm{~g} / \mathrm{L}$ & $125.00 \mathrm{~g} / \mathrm{L}$ & $122.00 \mathrm{~g} / \mathrm{L}$ \\
$\mathrm{WBC}$ & $1.36 \times 10^{9} / \mathrm{L}$ & $3.33 \times 10^{9} / \mathrm{L}$ & $4.12 \times 10^{9} / \mathrm{L}$ & $5.04 \times 10^{9} / \mathrm{L}$ \\
$\mathrm{PLT}$ & $59.00 \times 10^{9} / \mathrm{L}$ & $135 \times 10^{9} / \mathrm{L}$ & $214 \times 10^{9} / \mathrm{L}$ & $175 \times 10^{9} / \mathrm{L}$ \\
\hline
\end{tabular}

Note: The pancytopenia is responding well to treatment. lymphoma. In present case, the immunostaining of bone marrow showed the negativity for b-FGF, TNF- $\alpha$, TGF- $\beta$, PDGF, IL-1 $\beta$, IL-2, IL-6, IL-10 with the improvement of MF, which suggested these cytokines may contribute to the development of MF. This case of bone marrow biopsy revealed diffuse fibrosis (MF-3) diagnosed with FL (3A, AnnArbor IVB). The patient presented enlargement of lymph nodes, for example in the bilateral cervical neck, bilateral axillae, mediastinum, retroperitoneum before treatment, accompanied with spleen enlargement. The metabolism of bone was elevated meanwhile. However, the lymph node, spleen and bone were normal after three courses of chemotherapy. We hypothesize that late disease easily complicates with myelofibrosis. This may be related to tumor cell invasion into the bone marrow or cytokine released during lymphoma cell growth. Lymphoma cells may promote fibroblast proliferation and bone marrow collagen by secreting TGF- $\beta$ and b-FGF, leading to the development of MF.

In conclusion, our experience is limited to one patient, further research is needed to explore the potential pathogenesis of the FL with MF. 

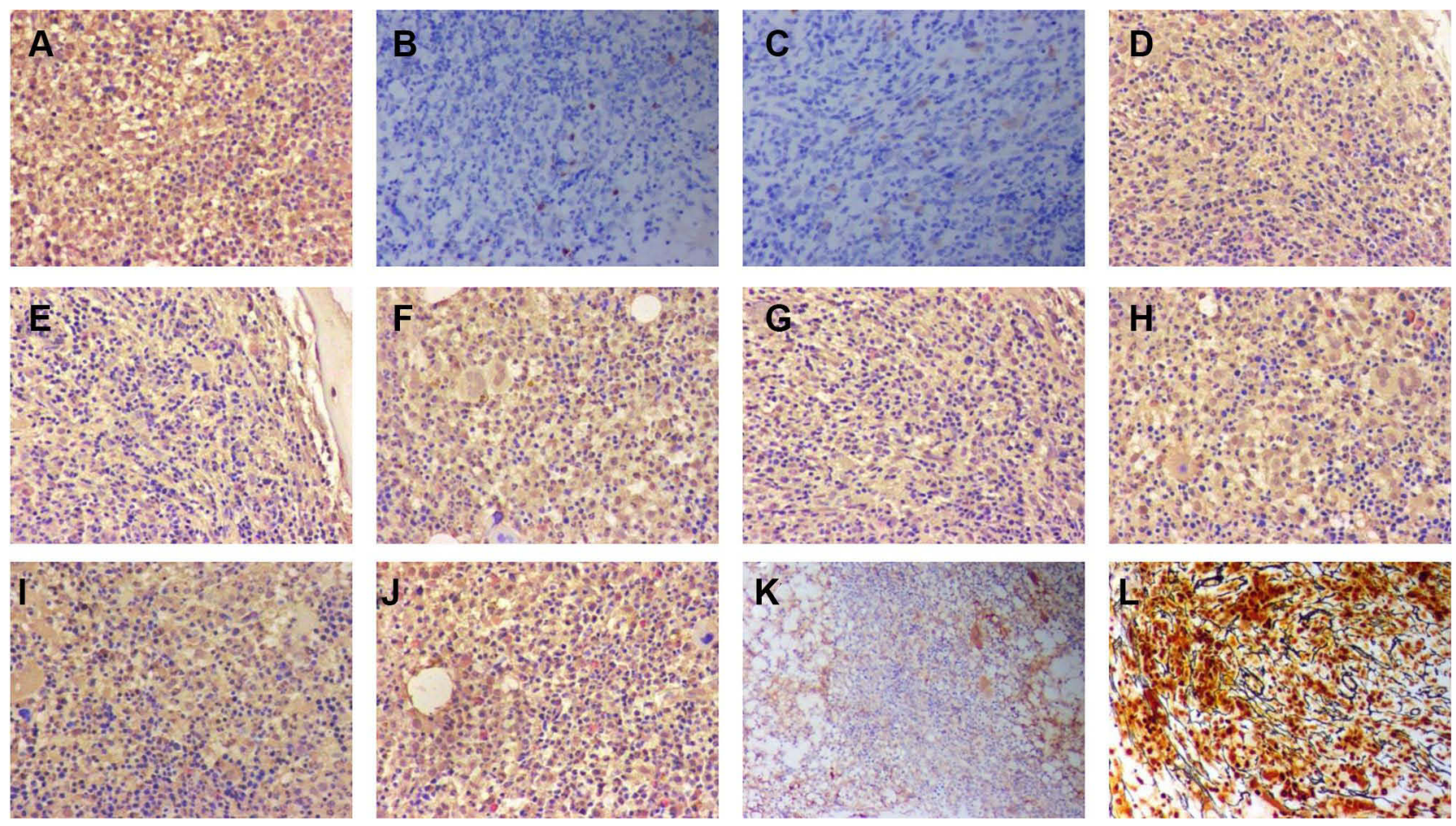

Figure 7 The immunostaining of bone marrow after one course of chemotherapy. (A) (b-FGF; $\times 200)$, positive; (B) (CDI9; $\times 200)$, negative; (C) $(C D I I 7 \times 200)$, negative; (D) (IL-I $\beta ; \times 200)$, positive; (E) (IL-2; $\times 200)$, positive; (F) (IL-6; $\times 200)$, positive; (G) (IL-10; $\times 200)$, positive; (H) (PDGF $\times 200)$, positive; (I) (TGF- $\beta \times 200)$, positive; (J) (TNF- $\alpha \times 200)$, positive; (K) (VEGF× 100), positive; (L) reticular fiber staining $\times 200$, MF-I.
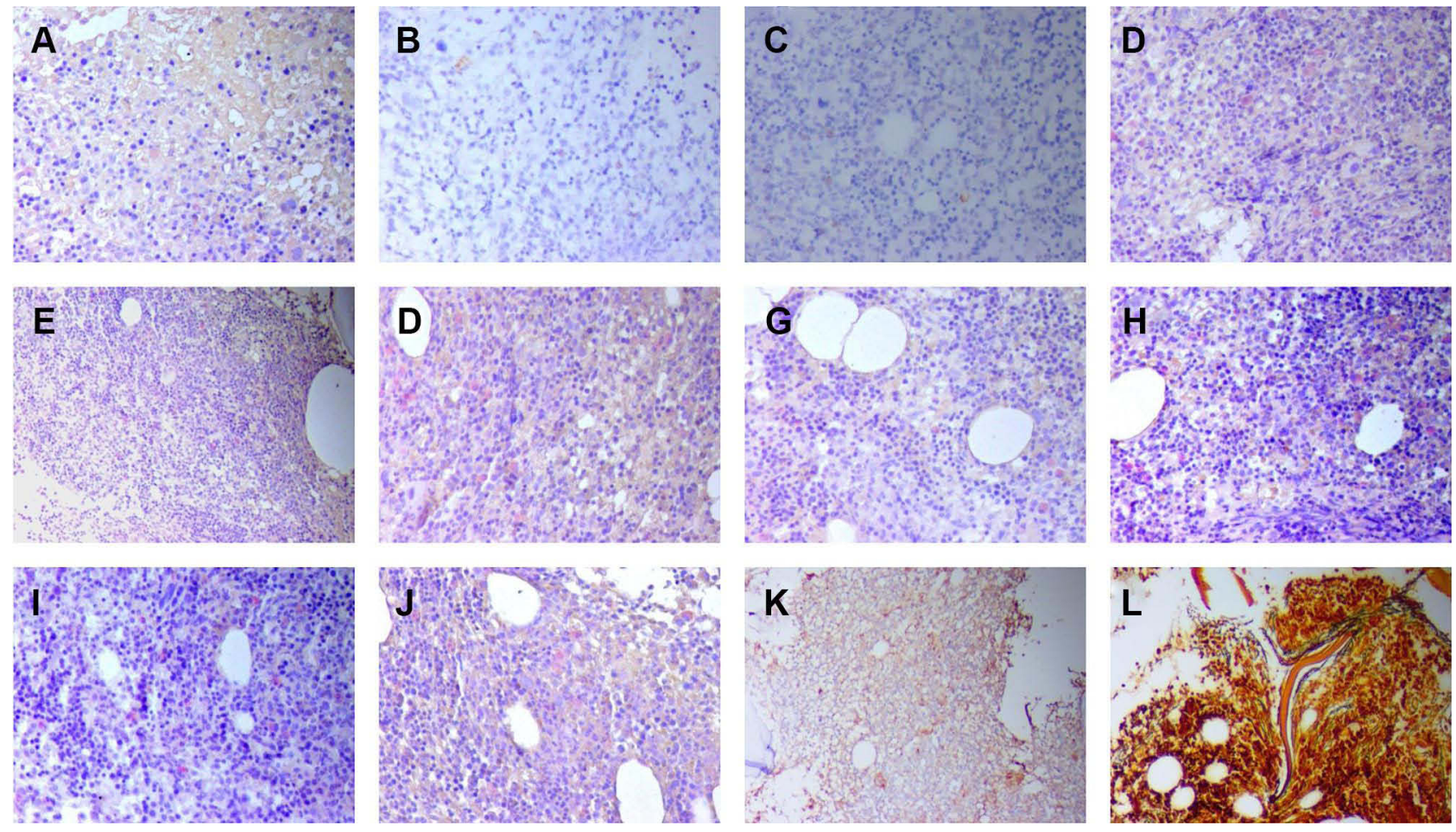

Figure 8 The immunostaining of bone marrow after two courses of chemotherapy. (A) (b-FGF; $\times 200)$, negative; (B) (CDI9;×200), negative; (C) (CDII7; ×200), negative; (D) (IL-I $\beta ; \times 200)$, negative; (E) (IL-2; $\times 100)$, negative; (F) (IL-6; $\times 200)$, negative; (G) (IL-10; $\times 200)$, negative; (H) $($ PDGF $\times 200)$, negative; (I) (TGF- $\beta \times 200)$, negative; (J) (TNF$\alpha \times 200)$, negative; (K) (VEGF $\times 100)$, positive; (L) reticular fiber staining I00×, MF 0-I. 


\section{Ethical Approval}

The publication of this case report gained ethical approval from the Ethics Committee of Hebei General Hospital.

\section{Consent for Publication}

Written informed consent was obtained from the patient for publication of this paper and any accompanying images.

\section{Informed Consent}

Written informed consent for this case report has been obtained from the patient.

\section{Acknowledgments}

This study was financially supported by the Department of science and technology of Hebei Province Plan Project (Priority research and development Project 18277720D).

\section{Disclosure}

The authors report no conflicts of interest in this work.

\section{References}

1. Swerdlow Steven H, Campo E, Pileri Stefano A, et al. The 2016 revision of the World Health Organization classification of lymphoid neoplasms. Blood. 2016;127(20):2375-2390. doi:10.1182/blood-2016-01-643569

2. Freedman A, Jacobsen E. Follicular lymphoma: 2020 update on diagnosis and management. Am J Hematol. 2020;95(3):316-327. doi:10.1002/ajh.25696

3. Liu YL, Wang WJ, Wang XN. [Pathological characteristics of bone marrow in non-Hodgkin's lymphoma patients with secondary myelofibrosis and their relationship with prognosis]. Zhongguo Shi Yan Xue Ye Xue Za Zhi. 2015;23(3):674-678. Chinese.

4. Green Michael R. Chromatin modifying gene mutations in follicular lymphoma. Blood. 2018;131(6):595-604. doi:10.1182/blood-2017-08737361

5. Bae E, Park C-J, Cho Y-U, et al. Differential diagnosis of myelofibrosis based on WHO 2008 criteria: acute panmyelosis with myelofibrosis, acute megakaryoblastic leukemia with myelofibrosis, primary myelofibrosis and myelodysplastic syndrome with myelofibrosis Int $J$ Lab Hematol. 2013;35(6):629-636. doi:10.1111/ijlh.12101

6. Fu R, Yu H, Wu Y-H, Liu H, Shao Z-H. Hodgkin's lymphoma associated with myelofibrosis: a case report. Oncol Lett. 2015;10 (3):1551-1554. doi:10.3892/ol.2015.3438

7. Kuroda H, Abe T, Jomen W, et al. [Follicular lymphoma complicated with myelofibrosis and macroglobulinemia at initial presentation]. Rinsho Ketsueki. 2013;54(11):2068-2073. Japanese.
8. Tabata R, Tabata C, Nagai T, Yasumizu R. Follicular lymphoma with prominent fibrosis complicated by peripheral eosinophilia. Ann Hematol. 2012;91(6):965-967. doi:10.1007/s00277-011$1342-9$

9. Wang W, Dong L, Yin Q, Song Y, Wei X, Li Y. [Clinical analysis of 5 cases of lymphoma with myelofibrosis and literature review]. Zhonghua Xue Ye Xue Za Zhi. 2016;37(02):157-159. Chinese.

10. Kumagai T, Satoh Y, Koshiishi M, et al. 18F-FDG-PET/CT is effective in distinguishing myelofibrosis due to bone marrow infiltration of diffuse large B-cell lymphoma from triple-negative primary myelofibrosis. Jpn J Clin Hematol. 2017;58(3):228-232.

11. Tsutsui M, Yasuda H, Ota Y, Komatsu N. Splenic marginal zone lymphoma with prominent myelofibrosis mimicking triple-negative primary myelofibrosis. Case Rep Oncol. 2019;12(3):834-837. doi:10.1159/000504129

12. Arber DA, Orazi A, Hasserjian R, et al. The 2016 revision to the World Health Organization classification of myeloid neoplasms and acute leukemia. Blood. 2016;127(20):2391-2405. doi:10.1182/blood2016-03-643544

13. Rameshwar P, Oh HS, Yook C, Gascon P, Chang VT. Substance p-fibronectin-cytokine interactions in myeloproliferative disorders with bone marrow fibrosis. Acta Haematol. 2003;109(1):1-10. doi:10.1159/000067268

14. Sekiguchi Y, Shirane S, Shimada A, et al. Peripheral T cell lymphoma, not otherwise specified with myelofibrosis: report of a case with review of the literature. Int J Clin Exp Pathol. 2015;8(4):4186-4203.

15. Sekiguchi Y, Matsuzawa N, Shimada A, et al. Angioimmunoblastic T-cell lymphoma with intramedullary production of platelet-derived growth factor and possibly complicating myelofibrosis: report of a case with review of the literature. Int J Hematol. 2013;98 (2):250-257. doi:10.1007/s12185-013-1386-9

16. Kikukawa M, Umahara T, Kikawada M, et al. Peripheral T-cell lymphoma presenting as myelofibrosis with the expression of basic fibroblast growth factor. Geriatr Gerontol Int. 2009;9(4):395-398. doi:10.1111/j.1447-0594.2009.00556.x

17. Uehara E, Tasaka T, Matsuhashi Y, et al. Peripheral T-cell lymphoma presenting with rapidly progressing myelofibrosis. Leuk Lymphoma. 2003;44(2):361-363. doi:10.1080/1042819021000029966

18. Okabe S, Miyazawa K, Iguchi T, et al. Peripheral T-cell lymphoma together with myelofibrosis with elevated plasma transforming growth factor- $\beta 1$. Leuk Lymphoma. 2005;46(4):599-602. doi:10.1080/10428190400029809

19. Matsui K, Adachi M, Tominaga T, Shinohara K, Kamei T. Angioimmunoblastic $\mathrm{T}$ cell lymphoma associated with reversible myelofibrosis. Intern Med. 2008;47(21):1921-1924. doi:10.2169/ internalmedicine.47.1236

20. Matsunaga T, Takemoto N, Miyajima N, et al. Splenic marginal zone lymphoma presenting as myelofibrosis associated with bone marrow involvement of lymphoma cells which secrete a large amount of TGF-beta. Ann Hematol. 2004;83(5):322-325. doi:10.1007/s00277-0030806-y
OncoTargets and Therapy

\section{Publish your work in this journal}

OncoTargets and Therapy is an international, peer-reviewed, open access journal focusing on the pathological basis of all cancers, potential targets for therapy and treatment protocols employed to improve the management of cancer patients. The journal also focuses on the impact of management programs and new therapeutic agents and protocols on patient perspectives such as quality of life, adherence and satisfaction. The manuscript management system is completely online and includes a very quick and fair peer-review system, which is all easy to use. Visit http://www.dovepress.com/ testimonials.php to read real quotes from published authors. 